\title{
MALNUTRITION IS A MARKER OF MORTALITY IN CRITICALLY ILL CHILDREN WITH
} HYPERGLYCEMIA

\author{
H.P. Leite ${ }^{1}$, S.B. de Oliveira Iglesias ${ }^{1}$, J.C. Pacheco ${ }^{1}$, L.P. Lima ${ }^{1}$, W.B. de Carvalho ${ }^{2}$ \\ ${ }^{I}$ Pediatrics, Federal University of São Paulo, SP, ${ }^{2}$ Pediatrics, University of São Paulo, São Paulo, Brazil
}

Objective: To determine whether hyperglycemia is associated with poor outcome of children hospitalized in the ICU while taking into account the clinical severity and nutritional status.

Methods: A prospective cohort study was conducted on 221 children admitted to the ICU. Independent variables in the outcome analyses included hyperglycemia (blood glucose $>110 \mathrm{mg} / \mathrm{dl}$ ), severe hyperglycemia (blood glucose $>180 \mathrm{mg} / \mathrm{dl}$ ) during the first 72 hours after admission, age, gender, nutritional status, Pediatric Index of Mortality 2 and Pediatric Logistic Organ Dysfunction scores. The dependent variables were mortality, length of stay, and time on mechanical ventilation.

Results: $47.1 \%$ of patients were malnourished. Hyperglycemic peaks in the first 24, 48, and 72 hours were $123 \pm 28.7 \mathrm{mg} / \mathrm{dl}, 121 \pm 24.5 \mathrm{mg} / \mathrm{dl}$, and $119 \pm 21.8 \mathrm{mg} / \mathrm{dl}$, respectively. Severe hyperglycemia in the first 24 hours after admission was independently associated with organ dysfunction (OR 4.08, CI 95\% 1.87-8.88; $\mathrm{p}=$ $0.001)$ and with mortality $(\mathrm{OR}=4.35$, CI $95 \% 1.28-14.71, \mathrm{p}=0.018)$. In the multiple logistic regression model, adjusting for the severity of organ dysfunction, severe hyperglycemia in the first 24 hours of admission increased the mortality risk (OR 4.35 CI 95\% 1.29-14.71, $\mathrm{p}=0.018$ ). Adjusting for the same variable in the malnourished subgroup of patients, severe hyperglycemia in the first 24 hours was associated with an increased mortality (OR 5.41, CI 95\% 1.34-21.92, $\mathrm{p}=0.018$ ), where this was not observed in the well-nourished subgroup.

Conclusions: Malnourished patients with severe hyperglycemia in the first 24 hours are at a greater risk of mortality, independent of clinical severity. 